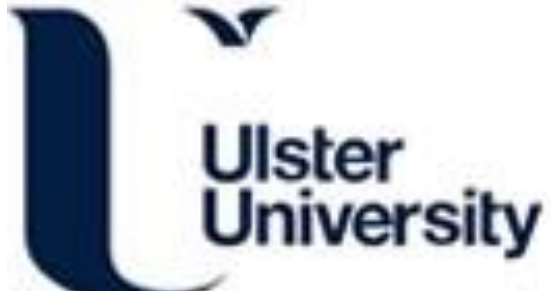

Slip-rate-dependent friction as a universal mechanism for slow slip events

Im, K., Saffer, D., Marone, C., \& Avouac, J. P. (2020). Slip-rate-dependent friction as a universal mechanism for slow slip events. Nature Geoscience, 13(10), 705-710. https://doi.org/10.1038/s41561-020-0627-9

Link to publication record in Ulster University Research Portal

\section{Published in:}

Nature Geoscience

Publication Status:

Published online: 07/09/2020

DOI:

10.1038/s41561-020-0627-9

\section{Document Version}

Author Accepted version

\section{General rights}

Copyright for the publications made accessible via Ulster University's Research Portal is retained by the author(s) and / or other copyright owners and it is a condition of accessing these publications that users recognise and abide by the legal requirements associated with these rights.

\section{Take down policy}

The Research Portal is Ulster University's institutional repository that provides access to Ulster's research outputs. Every effort has been made to ensure that content in the Research Portal does not infringe any person's rights, or applicable UK laws. If you discover content in the Research Portal that you believe breaches copyright or violates any law, please contact pure-support@ulster.ac.uk. 


\title{
Slip rate-dependent friction as a universal mechanism for slow slip events
}

\author{
Kyungjae $\operatorname{Im}^{1,2^{*}}$, Demian Saffer $^{3}$, Chris Marone ${ }^{3}$, Jean-Philippe Avouac ${ }^{1}$
}

${ }^{1}$ Geology and Planetary Science Division, California Institute of Technology, Pasadena, CA 91125, United States

${ }^{2}$ Department of Energy and Mineral Engineering, EMS Energy Institute, and G3 Center, Pennsylvania State University, University Park, PA 16802, United States

${ }^{3}$ Department of Geosciences, EMS Energy Institute, and G3 Center, The Pennsylvania State University, University Park, PA 16802, United States

*Correspondence to: kjim@caltech.edu

A growing body of observations worldwide has documented fault slip transients that radiate little or no seismic energy. The mechanisms that govern these slow slip events and their wide range of depths, slip rates, durations, stress drops, and recurrence intervals remain poorly known. Here we show that slow slip can be explained by a transition from rate-weakening frictional sliding at low slip rates toward rate-neutral or rate-strengthening behavior at higher slip rates, as has been observed experimentally. We use numerical simulations to illustrate that this rate-dependent transition quantitatively explains experimental data for natural fault rocks representative of materials in the source regions of slow slip events. With a standard constant-parameter rate-and-state friction law, slow slip events arise only near the threshold for slip instability. The inclusion of velocity dependent friction parameters significantly broadens the range of conditions for slow slip 
occurrence, and produces a wide range of event characteristics, including stress drop, duration, and recurrence, as are observed in nature. Upscaled numerical simulations that incorporate parameters consistent with laboratory measurements can reproduce geodetic observations of repeating slow slip events on tectonic faults. Our work offers an explanation for the ubiquitous occurrence of slow slip events in a broad spectrum of geologic environments.

Faults in nature can slip episodically during earthquakes, with slip rate typically larger than $1 \mathrm{~cm} / \mathrm{s}$, but also in much slower transient slip events that are essentially aseismic. These include slow slip events (SSEs) which last days to weeks and are often associated with low-amplitude seismic tremors ${ }^{1,2}$. SSEs have been widely observed spanning a range of depths along subduction plate interfaces including Cascadia ${ }^{2}, \mathrm{Mexico}^{3}, \mathrm{Japan}^{4}, \mathrm{Costa} \mathrm{Rica}^{5}$, and New Zealand ${ }^{6}$, as well as on continental transform faults including the San Andreas ${ }^{7}$ and North Anatolian Faults ${ }^{8}$. In some cases, these phenomena have been linked to elevated pore pressure based on theoretical considerations, their sensitivity to tidal stresses, and their spatial correlation with zones of high $V_{\mathrm{p}} / V_{\mathrm{s}}^{9-11}$.

SSEs result, like regular earthquakes, from unstable frictional sliding ${ }^{12,13}$. Previous studies have shown that SSEs can arise in numerical simulations based on the rate-and-state ${ }^{14}$ (RSF) formalism. Within the RSF framework, regular earthquakes (stick-slip) occur if the slipping area is larger than a critical patch size, and SSEs arise if the system is near critical. However, in this context, SSEs should be observed only over a very narrow range of parameters for which the fault lies precisely at, or very near the stable-unstable transition ${ }^{12,13}$ (Figs. 1\&2). This contrasts with ubiquitous occurrence of SSEs spanning a diversity of geological environments in nature. 
Recent laboratory experiments also document a wide range of slow-slip behaviors, with a gradual evolution from stable sliding to slow stick-slip and ultimately to fast slip ${ }^{15-19}$. This laboratory work, together with the widespread occurrence of slow slip in nature, suggests a role for processes other than those represented by standard friction on a homogeneous fault - such as fluid-assisted dilation hardening ${ }^{20}$, geologic heterogeneities ${ }^{21}$, or more complex frictional rheology such as sliding rate dependence of RSF parameters ${ }^{22-24}$.

In RSF theory, a critical fault weakening rate as a function of slip (characterized by $K_{\mathrm{c}} \sim(a-$ b) $\sigma^{\prime} / D_{\mathrm{c}}$, see Methods) determines frictional stability ${ }^{25}$. In the standard form of RSF, the rate parameter $(a-b)$ and critical distance $\left(D_{\mathrm{c}}\right)$ are constant and independent of sliding velocity. However, recent laboratory measurements on both natural and synthetic fault gouges, including drill core from faults that are known to host SSEs, indicate that these parameters actually vary systematically with slip velocity ${ }^{26-28}$. The velocity dependence of $D_{\mathrm{c}}$ and $a-b$ was reported more than a decade ago for some materials ${ }^{29,30}$, and has been speculated as a potential explanation for episodic slow slip ${ }^{22-24}$. These results suggest qualitatively that the increased stability at high slip velocity would suppress acceleration of slip, and accordingly widen the range of conditions for slow earthquake generation. Numerical simulations in $1 \mathrm{D}$ and 2D have successfully produced slow slip evolution and propagation by incorporating velocity-dependent stability criteria ${ }^{22,24}$. Here, we investigate this hypothesis further by taking advantage of newly available laboratory data from natural fault zones that host slow earthquakes and comparing observations of SSEs with numerical simulations. The dynamic simulations are used to first reproduce the behavior observed in the laboratory ${ }^{16}$ and second to upscale to in situ fault zone conditions.

\section{Numerical Simulations of Laboratory Observations}


Our simulations for both constant (Fig. 1a) and velocity-dependent (Fig. 1b) RSF parameters are consistent with the theoretically defined stability criterion ${ }^{25}\left(\kappa=K / K_{c}=1\right.$; bold black lines in Fig. 1a \& b). Note that $K_{c}$ must be evaluated in a general form (see Methods; also ref 25) to account for rate-dependent RSF parameters. All cases with $\kappa<1$ converge toward repeating unstable slip (filled circles), whereas all cases with $\kappa>1$ converge to stable sliding (empty circles). In both cases, and as predicted by theory, slip transitions from stable to unstable as the normal stress is increased. In the experimental data ${ }^{16}$, the transition occurs at higher normal stress when the loading rate is increased; i.e. slip stabilizes at higher velocity (Extended Data Fig. 2a). This is not expected for constant parameter (regular) RSF, because the critical stiffness $K_{\mathrm{c}}$ is only expected to increase with slip velocity (Equation (6) in Methods). The observations are, however, consistent with a rate dependence of $D_{\mathrm{c}}$ and $a-b$, and this behavior is reproduced by simulations that account for this effect (Extended Data Fig. 2).

Another important difference is that constant RSF parameters predict an abrupt transition from steady sliding to fast earthquake-like stick-slip events, whereas rate dependent RSF parameters predict a more gradual transition (blue regions in Fig. 1b) and a broader range of loading velocities and normal stresses that yield a spectrum of slow slip events, consistent with field and lab results ${ }^{15-19}$. This difference is also evident from comparison of time series of both normalized shear stresses and the velocity of unstable sliding closest to the stability boundary $(\kappa=1)$ (Figs. $1 \mathrm{c}$ and $1 \mathrm{~d})$. Constant parameter simulations for the laboratory experimental conditions produce regular stick slip with peak velocity $20 \mathrm{~cm} / \mathrm{s}$ and slip duration $\sim 1 \mathrm{~ms}$ (Fig. 1c). In contrast, the velocity dependent parameter cases result in slow events with peak velocity of $\sim 80 \mu \mathrm{m} / \mathrm{s}$ and slip duration of $\sim 1 \mathrm{~s}$ (Fig. 1d). 
The expansion of the slow earthquake domain is particularly evident when simulations for a given loading rate are compared to laboratory experiments as a function of $\kappa$ (Fig. 2).

Simulations with velocity dependent RSF parameters agree much better with the laboratory results. The constant parameter case exhibits an abrupt transition at $\kappa=1$ (the stability threshold), resulting in $2 \sim 3$ orders of magnitude larger peak velocities (Fig. 2a) and 3 5 times larger stress drop (Fig. 2b) than the laboratory observations. In contrast, cases with velocity dependent RSF

95 parameters produce a gradual evolution of slip behavior as $\kappa$ approaches unity, in significantly better agreement with the laboratory experimental data. We note that the fit to laboratory data is not perfect; for $V_{\text {peak }}>1 \mathrm{~mm} / \mathrm{s}$, laboratory measurements of peak velocity are slower than model predictions (Fig. 2a). The overprediction of peak velocity may be explained by finite sampling frequency, derivation of velocity from discrete measurements in the lab, or other factors 100 unaccounted for in our analysis.

Our results also demonstrate that the peak slip velocity in slow stick slip events remains consistently lower than a commonly reported "cutoff velocity" that has been inferred at the transition from negative $(a-b<0)$ to positive $(a-b>0)$ rate-dependence of friction; furthermore, such a transition is not necessarily required to produce a spectrum of slow stick slip. This arises

105 because slip behavior exhibits a strong dependence on the rate of friction change with velocity (second term in Equation (10) in Methods) as well as the absolute value of rate-dependence.

\section{Upscaled Simulations and Application to Subduction Zones}

With a spring-slider approximation approach, we conducted multiple simulations with parameters representative of a generic subduction zone (Fig. 3a\&b), modified from the parameters of Scholz ${ }^{31}$ for regular (constant parameter) RSF friction. At low slip rate $(V<<$ $\left.V_{\mathrm{a}}=10^{-9} \mathrm{~m} / \mathrm{s}\right)$, steady-state friction is assumed to be rate-weakening $\left(a_{0}-b<0\right)$ between $7.5 \mathrm{~km}$ 
and $37.5 \mathrm{~km}$ depths, and rate-strengthening $\left(a_{0}-b>0\right)$ above and below this. The value of $a_{0}-b$ is constant and set to -0.003 between $15 \mathrm{~km}$ and $30 \mathrm{~km}$, and it varies linearly with depth elsewhere (Fig. 3b). We consider two scenarios: one in which pore pressure is $70 \%$ of the lithostatic pressure, presumably representative of the typical pore pressure along subduction megathrusts ${ }^{32}$; and a second case in which the pore pressure is set to $95 \%$ of the lithostatic pressure, which falls in the range of pore pressures approaching lithostatic values as suggested on the basis of forearc wedge taper angles and geophysical survey data ${ }^{10,32}$. We then consider the additional effect of a velocity dependence of $a-b$ and $D_{\mathrm{c}}$, and explore a parameter space consistent with recently 120 reported laboratory data for real fault rocks ${ }^{27,30}$.

With regular RSF, the entire rate-weakening domain between 7.5-37.5 km depth produces simulated stick-slip events with high peak velocity $(>1 \mathrm{~cm} / \mathrm{s})$ and relatively large stress drops $(>1 \mathrm{MPa})$, even if a high pore pressure is assumed (Figs. 3c\&3d). In order to generate slow stickslip events in a case where RSF parameters are constant, effective normal stress must remain very small, and near neutral RSF behavior (with $a-b<<10^{-4}$ ) is required. This condition is met only in a very narrow zone at the transition from the rate-strengthening to the rate-weakening behavior that is not resolved with our simulations. This result is consistent with previously reported fault plane simulation results ${ }^{13}$ showing that the range of fault length (stiffness) hosting slow slip is too small to be explained by standard constant parameter $\mathrm{RSF}^{13}$.

130 However, with velocity dependent RSF parameters, slow slip transients (with velocities similar to those in subduction zone SSEs; $1 \mathrm{~nm} / \mathrm{s}-1 \mu \mathrm{m} / \mathrm{s}$ ) are simulated over a considerably broader region spanning this transition zone, and with a wider range of event characteristics (Fig. 3). Notably, all of our simulation results with velocity dependent $a-b$ and $D_{\text {c }}$ yield $V_{\text {peak }}<1 \mathrm{~mm} / \mathrm{s}$, which we regard as "slow" relative to the $\mathrm{cm} /$ to $\mathrm{m} / \mathrm{s}$ slip velocities typical of ordinary 
earthquakes (Fig. 3c, red and blue curves). Although not required, higher pore pressure (lower effective normal stress) leads to a decreased peak slip velocity, and hence further broadens the region where slow slip occurs. Stress drop and recurrence interval are also sensitive to pore pressure (Figs. 3d\&3e), such that modest variations are able to produce simulated SSE that span a wide spectrum of rates, recurrence, and durations, consistent with the broad range of observed SSE behavior in nature.

\section{Comparison to natural slow slip events}

We considered case examples of well-characterized repeating SSEs in Cascadia ${ }^{33}$, Hikurangi ${ }^{6}$ (New Zealand), Ryukyu ${ }^{34}$ (Japan) and the Guerrero gap ${ }^{35}$ (Mexico) (Fig. 4). These examples span a wide range of depths, from near surface to $\sim 40 \mathrm{~km}$, and a range of recurrence intervals from sub-annual to decadal. We explored a parameter space consistent with the laboratory constraints $^{16,27,29}$ (see Extended Data Fig. 3B). Assuming that GPS displacement is proportional to fault slip, we successfully reproduce the evolution and behavior of these well-characterized SSEs with only modest adjustment of the model parameters within the range of experimental data, using a single-degree-of-freedom approximation. Given that this approximation is not strictly valid as it is clear that SSE can expand and propagate ${ }^{33}$, we carried out tests (Extended data Fig. 5), which indicate that it is still a reasonable first-order approximation for typical rates of propagation of SSEs.

Interestingly, our simulations also capture the asymmetric fast-acceleration and slowdeceleration characteristics of SSEs, which are most prominent in the Ryukyu and to a lesser degree the Mexican examples, and which can be observed in most of the GPS stations regardless of their relative locations to the slipping patch $^{36,37}$. This behavior emerges in our simulations as a result of fundamental characteristics of RSF that lead to fast acceleration at $(a-b)<0$ (nucleation 
phase in simulation), and slow deceleration for $(a-b) \approx 0$ or $(a-b)>0$ (when slip decelerates). However, we acknowledge that other factors, including 3-dimensional effects that are ignored in our simulations, could also help explain the asymmetric slip-velocity pulse of SSEs in nature.

We do not claim that the model parameters used in each of these simulations are uniquely constrained. However, we emphasize that a framework with rate-dependent $a-b$ and $D_{\mathrm{c}}$, which is consistent with recent laboratory measurements for materials from natural tectonic faults that host SSEs, together with low effective normal stress (or, more precisely a high ratio of shear stress to fault zone frictional strength), can produce a broad range of episodic slow slip events with characteristics comparable to those of observed SSEs.

Our work quantitatively illuminates one potential underlying mechanism explaining the widespread occurrence and broad spectrum of SSE slip rates. We find that recurrent slow slip can occur over a much wider range of conditions if RSF formalism is adjusted so that frictional sliding transitions from rate-weakening at low slip rate to lesser rate-weakening or rate-neutral behavior at higher slip rate, as is observed in laboratory experiments on samples representative of lithologies hosting SSEs in nature ${ }^{27,28}$. Our results provide a resolution to the apparent paradox that SSE are widespread globally and occur over a broad range of depths and geologic environments, and span a spectrum of slip rates and durations, yet the predictions of regular RSF friction laws restrict their occurrence to a very narrow set of conditions. 


\section{References}

1. Obara, K., Hirose, H., Yamamizu, F. \& Kasahara, K. Episodic slow slip events accompanied by non-volcanic tremors in southwest Japan subduction zone. Geophysical Research Letters 31, doi:L23602 10.1029/2004g1020848 (2004).

2. Dragert, H., Wang, K. \& James, S. T. A silent slip event on the deeper Cascadia subduction interface. Science 292, 1525-1528 (2001).

3. Kostoglodov, V. et al. A large silent earthquake in the Guerrero seismic gap, Mexico. Geophysical Research Letters 30, doi:10.1029/2003g1017219 (2003).

4. Kano, M. et al. Development of a Slow Earthquake Database. Seismological Research Letters 89, 1566-1575, doi:10.1785/0220180021 (2018).

5. Jiang, Y. et al. Slow slip events in Costa Rica detected by continuous GPS observations, 2002-2011. Geochem. Geophys. Geosyst. 13, doi:10.1029/2012gc004058 (2012).

6. Wallace, L. M. et al. Slow slip near the trench at the Hikurangi subduction zone, New Zealand. Science 352, 701-704, doi:10.1126/science.aaf2349 (2016).

7. Tymofyeyeva, E. et al. Slow Slip Event On the Southern San Andreas Fault Triggered by the 2017 Mw8.2 Chiapas (Mexico) Earthquake. J. Geophys. Res. Solid Earth 124, 9956-9975 (2019).

8. Rousset, B. et al. An aseismic slip transient on the North Anatolian Fault. Geophys. Res. Lett. 43, 3254-3262 (2016).

9. Hawthorne, J. C. \& Rubin, A. M. Tidal modulation of slow slip in Cascadia. Journal of Geophysical Research-Solid Earth 115, doi:10.1029/2010jb007502 (2010).

10. Kodaira, S. et al. High pore fluid pressure may cause silent slip in the Nankai Trough. Science 304, 1295-1298 (2004). 
200 11. Gao, X. \& Wang, K. L. Rheological separation of the megathrust seismogenic zone and episodic tremor and slip. Nature 543, 416-+, doi:10.1038/nature21389 (2017).

12. Liu, Y. J. \& Rice, J. R. Aseismic slip transients emerge spontaneously in three-dimensional rate and state modeling of subduction earthquake sequences. Journal of Geophysical Research-Solid Earth 110, doi:B08307 10.1029/2004jb003424 (2005).

13. Rubin, A. M. Episodic slow slip events and rate-and-state friction. Journal of Geophysical Research-Solid Earth 113, doi:B1 1414 10.1029/2008jb005642 (2008).

14. Marone, C. Laboratory-derived friction laws and their application to seismic faulting. Annual Review of Earth and Planetary Sciences 26, 643-696 (1998).

15. Scuderi, M. M., Collettini, C., Viti, C., Tinti, E. \& Marone, C. Evolution of shear fabric in granular fault gouge from stable sliding to stick slip and implications for fault slip mode. Geology 45, 731-734, doi:10.1130/g39033.1 (2017).

16. Leeman, J. R., Marone, C. \& Saffer, D. M. Frictional Mechanics of Slow Earthquakes. Journal of Geophysical Research-Solid Earth 123, 7931-7949, doi:10.1029/2018jb015768 (2018).

17. Leeman, J. R., Saffer, D. M., Scuderi, M. M. \& Marone, C. Laboratory observations of slow earthquakes and the spectrum of tectonic fault slip modes. Nature Communications 7, doi:10.1038/ncomms11104 (2016).

18. Baumberger, T., Heslot, F. \& Perrin, B. Crossover from creep to inertial motion in friction dynamics. Nature 367, 544-546 (1994).

19. Mitchell, E. K., Fialko, Y. \& Brown, K. M. Frictional properties of gabbro at conditions corresponding to slow slip events in subduction zones. Geochemistry, Geophys. Geosystems $16,4006-4020$ (2015). 
20. Segall, P., Rubin, A. M., Bradley, A. M. \& Rice, J. R. Dilatant strengthening as a mechanism for slow slip events. Journal of Geophysical Research-Solid Earth 115, doi:B12305 10.1029/2010jb007449 (2010).

21. Skarbek, R. M., Rempel, A. W. \& Schmidt, D. A. Geologic heterogeneity can produce aseismic slip transients. Geophysical Research Letters 39, doi:10.1029/2012g1053762 (2012).

22. Shibazaki, B. \& Shimamoto, T. Modelling of short-interval silent slip events in deeper subduction interfaces considering the frictional properties at the unstable-stable transition regime. Geophysical Journal International 171, 191-205, doi:10.1111/j.1365246X.2007.03434.X (2007).

23. Kaproth, B. M. \& Marone, C. Slow Earthquakes, Preseismic Velocity Changes, and the Origin of Slow Frictional Stick-Slip. Science 341, 1229-1232, doi:10.1126/science.1239577 (2013).

24. Rubin, A. M. (2011). Designer friction laws for bimodal slow slip propagation speeds. Geochemistry, Geophysics, Geosystems, 12(4). https://doi.org/doi:10.1029/2010GC003386

25. Rice, J. R. \& Ruina, A. L. Stability of Steady Frictional Slipping. Journal of Applied Mechanics-Transactions of the Asme 50, 343-349 (1983).

26. Ikari, M. J., Saffer, D. M. \& Marone, C. Frictional and hydrologic properties of clay-rich fault gouge. Journal of Geophysical Research-Solid Earth 114, doi:10.1029/2008jb006089 (2009).

27. Ikari, M. J. \& Saffer, D. M. Comparison of frictional strength and velocity dependence between fault zones in the Nankai accretionary complex. Geochem. Geophys. Geosyst. 12, doi:10.1029/2010gc003442 (2011). 
28. Rabinowitz, H. S. et al. Frictional Behavior of Input Sediments to the Hikurangi Trench, New Zealand. Geochem. Geophys. Geosyst. 19, 2973-2990, doi:10.1029/2018gc007633 (2018).

29. Mair, K. \& Marone, C. Friction of simulated fault gouge for a wide range of velocities and normal stresses. Journal of Geophysical Research-Solid Earth 104, 28899-28914, doi:10.1029/1999jb900279 (1999).

30. Saffer, D. M. \& Marone, C. Comparison of smectite- and illite-rich gouge frictional properties: application to the updip limit of the seismogenic zone along subduction megathrusts. Earth and Planetary Sciences Letters. 215, 219-235 (2003).

31. Scholz, C. H. Earthquakes and friction laws. Nature 391, 37-42 (1998).

32. Saffer, D. M. \& Tobin, H. J. Hydrogeology and Mechanics of Subduction Zone Forearcs : Fluid Flow and Pore Pressure. Annu. Rev. Earth Planet. Sci. 39, 157-86 (2011).

33. Michel, S., Gualandi, A., \& Avouac, J.-P. (2019). Similar scaling laws for earthquakes and Cascadia slow-slip events. Nature, 574(7779), 522-526. https://doi.org/10.1038/s41586-0191673-6

34. Kano, M., Fukuda, J., Miyazaki, S. \& Nakamura, M. Spatiotemporal Evolution of Recurrent Slow Slip Events Along the Southern Ryukyu Subduction Zone, Japan, From 2010 to 2013. J. Geophys. Res. Solid Earth 123, 7090-7107 (2018).

35. Gualandi, A., Perfettini, H., Radiguet, M., Cotte, N. \& Kostoglodov, V. GPS deformation related to the M-w 7.3, 2014, Papanoa earthquake (Mexico) reveals the aseismic behavior of the Guerrero seismic gap. Geophysical Research Letters 44, 6039-6047, doi:10.1002/2017g1072913 (2017). 
36. Radiguet, M., Cotton, F., Vergnolle, M., Campillo, M., Walpersdorf, A., Cotte, N., \& Kostoglodov, V. (2012). Slow slip events and strain accumulation in the Guerrero gap, Mexico. Journal of Geophysical Research: Solid Earth, 117(B4). https://doi.org/doi:10.1029/2011JB008801

37. Heki, K., \& Kataoka, T. (2008). On the biannually repeating slow-slip events at the Ryukyu Trench, southwestern Japan. Journal of Geophysical Research: Solid Earth, 113(B11). https://doi.org/doi:10.1029/2008JB005739

\section{Corresponding Author}

Correspondence to Kyungjae Im (kjim@caltech.edu)

\section{Acknowledgments}

We thank to John Leeman, Sylvain Michel and Adriano Gualandi for sharing data. This study was supported by NSF EAR-1821853 to J.-P.A., NSF EAR-1616664 and OCE-1334436 to D.S., NSF EAR-1763305 and EAR-1520760 to C.J.M.

\section{Author contributions:}

K.J.I. led the numerical modeling effort and writing of the manuscript. All authors contributed to the interpretation of modeling results and writing the manuscript. D.S. and C.J.M. initiated the study and contributed to experimental data analysis. K.J.I and J-P.A. led GPS data analysis.

\section{Figure Captions}


Fig. 1. Conditions for episodic slow slip. Evolution of modeled peak slip velocity for constant RSF parameters (a) and velocity dependent $D_{\mathrm{c}}$ and $a(\mathbf{b})$. See Extended Data Fig. 1 for cases showing the separate effects of velocity dependence of $D_{c}$ and $a$. Filled circles represent unstable periodic oscillations (e.g., in Panel c\&d). Empty circles denote stable sliding. Bold black line denotes analytically calculated stability criterion $(\kappa=1)^{25}$. c, d: limit cycle oscillation of normalized shear stress (black), $K\left(\delta_{\mathrm{lp}}-\delta\right) / \sigma$, and velocity (red) for closest case to $\kappa=1$ at $V_{1}=10^{-5}$ $\mathrm{m} / \mathrm{s}$. See methods for details.

Fig. 2. Peak velocity (a) and normalized stress drop (b) as a function of $\boldsymbol{\kappa}$. The loading velocity is $10 \mu \mathrm{m} / \mathrm{s}$. For constant and velocity dependent $a$ and $D_{c}$ we use the same parameters as in Fig. 1 (see Methods for detailed input parameters). X-axis is normalized by the normal stress at the stability transition $(\kappa=1)$; upper $\mathrm{x}$ axis shows corresponding values of $\kappa$. Yellow stars denote experimental results ${ }^{16}$. Models with rate-dependent RSF parameters predict slow stick $\operatorname{slip}(V<1 \mathrm{~mm} / \mathrm{s})$ for values of $\kappa$ as low as $\sim 0.7$.

Fig 3. Characteristics of stick-slip events as a function of depth for a generic subduction megathrust. Each circle in c, $\mathbf{d}$ and e represents single-degree-of-freedom simulation results using normal stress and $a_{0}-b$ shown in $\mathbf{a}$ and $\mathbf{b}$. Colored lines denote pore pressures $70 \%$ (blue) and 95\% (red) of lithostatic stress. Red and blue line in $\mathbf{b}$ represent inverse of $\kappa$ (unstable at positive). c: Simulated peak slip velocity d: stress drop e: recurrence for velocity dependent parameters (both $a$ and $D_{\mathrm{c}}$; colored) and constant parameters (regular RSF; grey). 
Fig. 4. Comparison with observed Slow Slip Events. Estimated slow slip history (colored dots) and simulations (black lines) for examples of repeating SSEs observed at the Cascadia ${ }^{33}$ (a), Hikurangi $^{6}(\mathbf{b})$, Ryuku$^{34}(\mathbf{c})$ and Mexican megathrusts ${ }^{35}$ (d). (e): schematic section of subduction megathrust showing the estimated depths of SSE for the case examples and equivalent fault length used in the simulations $(L=50 \mathrm{~km}$ for the Guerrero gap on the Mexican megathrust, $L=$ $20 \mathrm{~km}$ for all others). Pore pressure is set to $97.5 \%, 70 \%, 95 \%$, and $95 \%$ of lithostatic pressure for the Cascadia, Hikurangi, Ryukyu and Guerrero gap simulations respectively. The velocity dependence of $a-b$ for each simulation (f) is color-coded as in the other panels and the symbols show experimental data for $a-b^{27}$ (also see extended Data Fig. 3).

\section{Methods}

Stability analysis with velocity-dependent $R S F$ parameters

In the RSF framework, friction is dependent on the slip velocity $(V)$ and a state variable $(\theta)^{14}$. The most widely used form is:

$$
\mu=\mu_{0}+a \ln \left(\frac{V}{V_{0}}\right)+b \ln \left(\frac{V_{0} \theta}{D_{c}}\right)
$$

where $\mu_{0}$ is a reference friction coefficient at reference velocity $V_{0}, D_{\mathrm{c}}$ is a critical slip distance, and $a$ and $b$ are empirical constants that define the direct and evolution effects, respectively. Negative values of the quantity $(a-b)$ represent velocity-weakening behavior, such that friction decreases with increased slip rate, and which is a prerequisite for unstable $\operatorname{slip}^{25,38}$. Positive values of $(a-b)$ indicate velocity-strengthening behavior, which is inherently stable. 
There are several formulations that define the evolution of frictional state $\theta$. In this work, we used the Ruina (slip) law which provides the best match to laboratory observations ${ }^{39,40}$

$$
\frac{d \theta}{d t}=-\frac{V \theta}{D_{c}} \ln \left(\frac{V \theta}{D_{c}}\right)
$$

Considering a one-degree of freedom spring-slider system with elastic interaction, the force balance governing motion can be written in dimensionless form as,

$$
\frac{M \ddot{\delta}}{\sigma^{\prime}}=\frac{K\left(\delta_{l p}-\delta\right)}{\sigma^{\prime}}-\mu
$$

where $M$ is mass per unit area $\left(\mathrm{kg} / \mathrm{m}^{2}\right), K$ is a spring stiffness expressed in units of shear stress per unit slip $(\mathrm{Pa} / \mathrm{m})$, and $\sigma^{\prime}$ is effective normal stress. Equation 3 shows that the normalized shear stress $K\left(\delta_{\mathrm{lp}}-\delta\right) / \sigma^{\prime}$ and friction $\mu$ decouple when the motion is dominated by inertia $\left(M \ddot{\delta} / \sigma^{\prime}\right)$. In this work, we use the normalized shear stress to define the magnitudes of stick-slip stress drop. In the stick-slip cycle, this normalized stress drop is almost identical to the friction drop unless inertia is significant ${ }^{41}$. The criterion for unstable sliding depends on the ratio between the system stiffness $(K)$ and the critical weakening rate (stiffness) of the fault zone $\left(K_{c}\right)$,

$$
\kappa=\frac{K}{K_{c}}
$$

Sliding is unstable for $\kappa<1$ and stable for $\kappa>1$ : For $\kappa<1$, fault weakening outpaces the reduction in stress due to elastic unloading during slip, resulting in a force imbalance and runaway instability ${ }^{31}$.

The critical stiffness $K_{\mathrm{c}}$ for a more generalized case with velocity dependent friction is ${ }^{25}$ :

$$
K_{c}=-\frac{\sigma^{\prime} V d \mu_{s s}(V) / d V}{D_{c}}\left[1+\frac{M V}{\sigma D_{c} \partial \mu(V, \theta) / \partial V}\right],
$$


where $\mu_{s s}(V)$ is the steady state friction at velocity $V$. Given Equations 1 and 2, the parameter $\mu_{s s}(V)$ can be written $\mu_{s s}=\mu_{0}+(a-b) \ln \left(V / V_{0}\right)$. For one state variable and regular RSF (constant $a, b$ and $D_{\mathrm{c}}$ ), Equation 5 simplifies to

$$
K_{c}=\frac{(b-a) \sigma^{\prime}}{D_{c}}\left[1+\frac{M V^{2}}{\sigma^{\prime} a D_{c}}\right]
$$

The second bracketed term in Equations 4 and 5 is a dimensionless inertial, "dynamic" parameter $^{41}$. The influence of this term can be observed in Fig. 1a as a velocity driven stability transition at $V_{l}>1 \mathrm{~cm} / \mathrm{s}$. In the other simulations this term is not significant due to the low loading rates and/or velocity dependence of the " $a$ " parameter. However, this only means that the inertial influence is insignificant in controlling stability transitions; mass (i.e. inertia) is essential to define slip motions (such as peak velocity, recurrence and friction drop) except for cases with extremely small accelerations (e.g. slow slip examples in Fig. 4).

\section{Stiffness and Mass}

For upscaled simulation of SSEs, we used a lumped stiffness and mass approximation. The stiffness $K$ of the spring-slider system representing the dynamics of slip on a fault of characteristic length $L$ embedded in an elastic medium is ${ }^{32}$ :

$$
K=\frac{G}{(1-v) L}
$$

where $G$ is shear modulus, $v$ is Poisson's ratio and $L$ is length of the fault patch. In all simulations, we used $K=4 \mathrm{MPa} / \mathrm{m}$. Assuming $v=0.25$, this lumped stiffness is equivalent to a fault patch $10 \mathrm{~km}$ length, within a crust with shear modulus of $30 \mathrm{GPa}$. 
We use $M=600000 \mathrm{~kg} / \mathrm{m}^{2}$, which is equivalent to a rock mass at $\sim 222 \mathrm{~m}$ depth (density $2700 \mathrm{~kg} / \mathrm{m}^{3}$ ). Note that the influence of the mass in all of our upscaled slow slip simulations (velocity dependent parameter cases in Fig. 3 and all simulations in Fig. 4) is negligible, as acceleration is low. To verify the negligible influence of mass for constant parameter cases, we conducted a set of simulations with 2 orders of magnitude variation in mass $(60000,600000$, $6000000 \mathrm{~kg} / \mathrm{m}^{2}$; Extended Data Fig. 4). The results show that this choice has little effect on the results; even for the largest mass there is an abrupt $V_{\text {peak }}$ jump at the transition.

\section{Velocity dependence}

We conduct our simulations with both constant and velocity-dependent friction parameters. On the basis of previous laboratory observations (see Extended Data Fig. 3) ${ }^{26-28,43-45}$, we define a log-linear dependence on velocity for the RSF parameters $a$ and $D_{c}$,

$$
\begin{aligned}
& a(V)=a_{0}+S_{a} \log _{10} \frac{V_{a}+V}{V_{a}}, \text { and } \\
& D_{c}(V)=D_{c 0}+S_{D c} \log _{10} \frac{V_{D c}+V}{V_{D c}} .
\end{aligned}
$$

In Equations 8 and 9, both parameters are constant for $V<V_{a}$ and $V<V_{D c}$ at the value of $a=a_{0}$ and $D_{c}=D_{c 0}$, and both increase log-linearly for $V>V_{a}$ and $V>V_{D c}$, with slope of $S_{a}$ and $S_{D c}$ per decade in velocity.

With velocity dependent parameters, an analytical expression defining the stability transition can be obtained following from ref. 25. The expanded expressions are:

$$
\frac{d \mu_{s s}}{d V}=\frac{a-b}{V}+\frac{S_{a} \log _{10} e}{V+V_{a}} \ln \frac{V}{V_{0}}
$$

and, 


$$
\frac{\partial \mu}{\partial V}=\frac{a}{V}+\frac{S_{a} \log _{10} e}{V+V_{a}} \ln \frac{V}{V_{0}}-\frac{S_{D c} \log _{10} e}{V+V_{D c}} \frac{b}{D_{c}}
$$

The critical stiffness $K_{c}$ can be expressed by substituting Equations 10 and 11 into Equation 5. Note that $V_{0}$, a reference velocity in RSF, now influences stability. Because the $\ln \left(V / V_{0}\right)$ term is directly multiplied by the parameter $a, V_{0}$ regulates the temporal influence of $a(V)$ on friction $(\mu)$ and therefore influences linear stability. In turn, this means that $V_{0}$ is not just a reference parameter but must have a physical meaning. However, defining $V_{0}$ is beyond the scope of this work. Here, we assume $V_{0}=10^{-9} \mathrm{~m} / \mathrm{s}$, which results in a stability transition that roughly fits laboratory observations for our velocity dependent parameter case (see Extended Data Fig. 2).

\section{Input parameters}

For simulations of laboratory experiments (Fig. 1\&2), we used parameters determined in experiments $^{16}$ (on fine granular quartz): $a=0.005, b=0.01, D_{\mathrm{c}}=10 \mu \mathrm{m}, K=2 \mathrm{GPa} / \mathrm{m}$ and $M=$ $200 \mathrm{~kg} / \mathrm{m}^{2}$. Here $M=200 \mathrm{~kg} / \mathrm{m}^{2}$ presents $4 \mathrm{~kg}$ of mass with $10 \mathrm{~cm} \times 20 \mathrm{~cm}$ of contact area. Considering the quasi-static critical stiffness $\left(K_{\mathrm{c}, \mathrm{qs}}=(b-a) \sigma / D_{\mathrm{c}}\right)$, our input parameters predict a stability transition at a normal stress of $4 \mathrm{MPa}$, in agreement with experimental results at low loading rates. For the velocity-dependent RSF parameter case, we set $a_{0}=0.005, S_{a}=0.0003$ per decade, $V_{a}=100 \mu \mathrm{m} / \mathrm{s}, D_{c 0}=10 \mu \mathrm{m}, S_{D c}=30 \mu \mathrm{m} /$ decade and $V_{D c}=100 \mu \mathrm{m} / \mathrm{s}$. This cut-off velocity $V_{\mathrm{a}}=V_{D c}=100 \mu \mathrm{m} / \mathrm{s}$ is determined from quartz-gouge experiments ${ }^{26}$ that used material similar to that for slow slip experiments ${ }^{16}$ (Extended Data Fig. 3A). The velocity-dependent $a$ and $D_{c}$ cases shown in Fig. 2 also use identical parameters except $S_{a}=0.0006$ and $S_{D c}=60 \mu \mathrm{m}$. 
include a constant $b=0.006$ and a depth dependent $a_{0}$ ranging from 0.009 to 0.003 ; $a_{0}$ increases linearly from $0 \sim 15 \mathrm{~km}$, remains constant between $15 \sim 30 \mathrm{~km}$, and decreases linearly from $30 \sim 45 \mathrm{~km}$ (Fig. 3b). Boundaries between velocity strengthening and weakening occur at depths of $7.5 \mathrm{~km}$ and $37.5 \mathrm{~km}$. We set $V_{\mathrm{a}}=V_{D c}=0.5 \mathrm{~nm} / \mathrm{s}$ and $S_{\mathrm{a}}=0.0013$ (Extended Data Fig. 3B), and $K=4 \mathrm{MPa} / \mathrm{m}$ (equivalent to a slip patch size, $L=10 \mathrm{~km}$ ).

Slow-slip data

In the case of Cascadia (Fig. 4), the slip model was derived from the inversion of geodetic time series $^{33}$. We selected the time history of slip on the northern segment of the Cascadia subduction zone, where the signal-to-noise ratio is best and nucleation occurs most frequently (at latitude $\sim 48^{\circ} \mathrm{N}$ in ref 28 ). In the other examples we selected representative time series at particular GPS stations. We rescaled each time series for slip on the megathrust on the basis of published fault slip inversions $s^{6,33,34,35}$ (second y-axis), assuming that repeated SSEs result from slip on the same segment and that GPS displacement varies linearly with fault slip. The long term trend has been subtracted from data.

\section{Simulation method}

We conduct simulations using a method that provides numerical stability in all slip modes - stable sliding, stick-slip and harmonic vibrations ${ }^{41,46}$. The velocity at each numerical step is constrained by the force balance. The time-discretized equation for displacement is

$$
\delta^{i+1}=\left[\delta^{i}-\left(\delta_{l p}^{i+1}-\mu^{i+1} \sigma / K\right)\right] \cos (\omega \Delta \mathrm{t})+\frac{V^{i}}{\omega} \sin (\omega \Delta t)+\left(\delta_{l p}{ }^{i+1}-\mu^{i+1} \sigma / K\right),
$$

where superscripts $i$ and $i+1$ denote successive time steps and $\omega$ is angular frequency defined as $\omega=\sqrt{K / M}$. (see Ref. 46 for detail). 
Numerical stability of the finite difference scheme described by Equation 12 requires $\Delta t$ $<<\omega$. This constraint is not troublesome if total simulation time is sufficiently small. Hence, this method can be employed to simulate laboratory experiments (Figs. 1 and 2) due to the high loading rate $\left(V_{1}>1 \mu \mathrm{m} / \mathrm{s}\right)$. However, the time step constraint becomes a problem for upscaled simulations (Figs. 3 and 4$)$ due to the long event recurrence ( $t_{\mathrm{r}}>100$ years). In upscaled simulations, Equation 12 is only adopted for the dynamic rupture phase. During static loading phases, Equations 1, 2 and 3 are solved by simple discretization and coupling. A varied time step is implemented in the range $2 \mu \mathrm{s}$ to $1 \mathrm{~ms}$ for laboratory parameter simulations and $100 \mathrm{~ms}$ to $10000 \mathrm{~s}$ for upscaled simulations.

\section{Data Availability}

GPS data for Hikurangi and Ryuku are available at Nevada Geodetic Laboratory

445 (geodesy.unr.edu). Mexico GPS data are available at Caltech Tectonics Observatory (http://www.tectonics.caltech.edu/resources/).

\section{Code Availability}

Simulation codes are available at Caltech data repository (data.caltech.edu).

\section{References}

38. Ruina, A. Slip instability and state variable friction laws. J. Geophys. Res. 88, 10359-10370 (1983).

39. Ampuero, J. P. \& Rubin, A. M. Earthquake nucleation on rate and state faults - Aging and slip laws. J. Geophys. Res. 110, 1-24 (2008). 
40. Bhattacharya P., Rubin, A. M., Bayart, E., Savage, H. M., and C. Marone, Critical evaluation of state evolution laws in rate and state friction: fitting large velocity steps in simulated fault gouge with time-, slip- and stress-dependent constitutive laws, J. Geophys. Res. Solid Earth, 120, 10.1002/2015JB012437 (2015).

41. Im, K., Marone, C. \& Elsworth, D. The transition from steady frictional sliding to inertiadominated instability with rate and state friction. J. Mech. Phys. Solids (2019). doi:10.1016/j.jmps.2018.08.026

42. Dieterich, J. H. Earthquake nucleation on faults with rate and state dependent strength. Tectonophysics 115-134 (1992). doi:10.1016/0040-1951(92)90055-B

43. Ikari, M. J., Marone, C., Saffer, D. M. \& Kopf, A. J. Slip weakening as a mechanism for slow earthquakes. Nature Geoscience 6, 468-472, doi:10.1038/ngeo1818 (2013).

44. Saffer, D. M. \& Wallace, L. M. The frictional, hydrologic, metamorphic and thermal habitat of shallow slow earthquakes. Nature Geoscience 8, 594-600, doi:10.1038/ngeo2490 (2015).

45. Ikari, M. J. \& Kopf, A. J. Seismic potential of weak, near-surface faults revealed at plate tectonic slip rates. Sci. Adv. 3, (2017).

46. Im, K., Elsworth, D., Marone, C. \& Leeman, J. The Impact of Frictional Healing on StickSlip Recurrence Interval and Stress Drop: Implications for Earthquake Scaling. Journal of Geophysical Research-Solid Earth 122, 10102-10117, doi:10.1002/2017jb014476 (2017).

47. Okada, Y. (1985). Surface deformation due to shear and tensile faults in a half-space. Bulletin of the Seismological Society of America, 75(4), 1135-1154. 

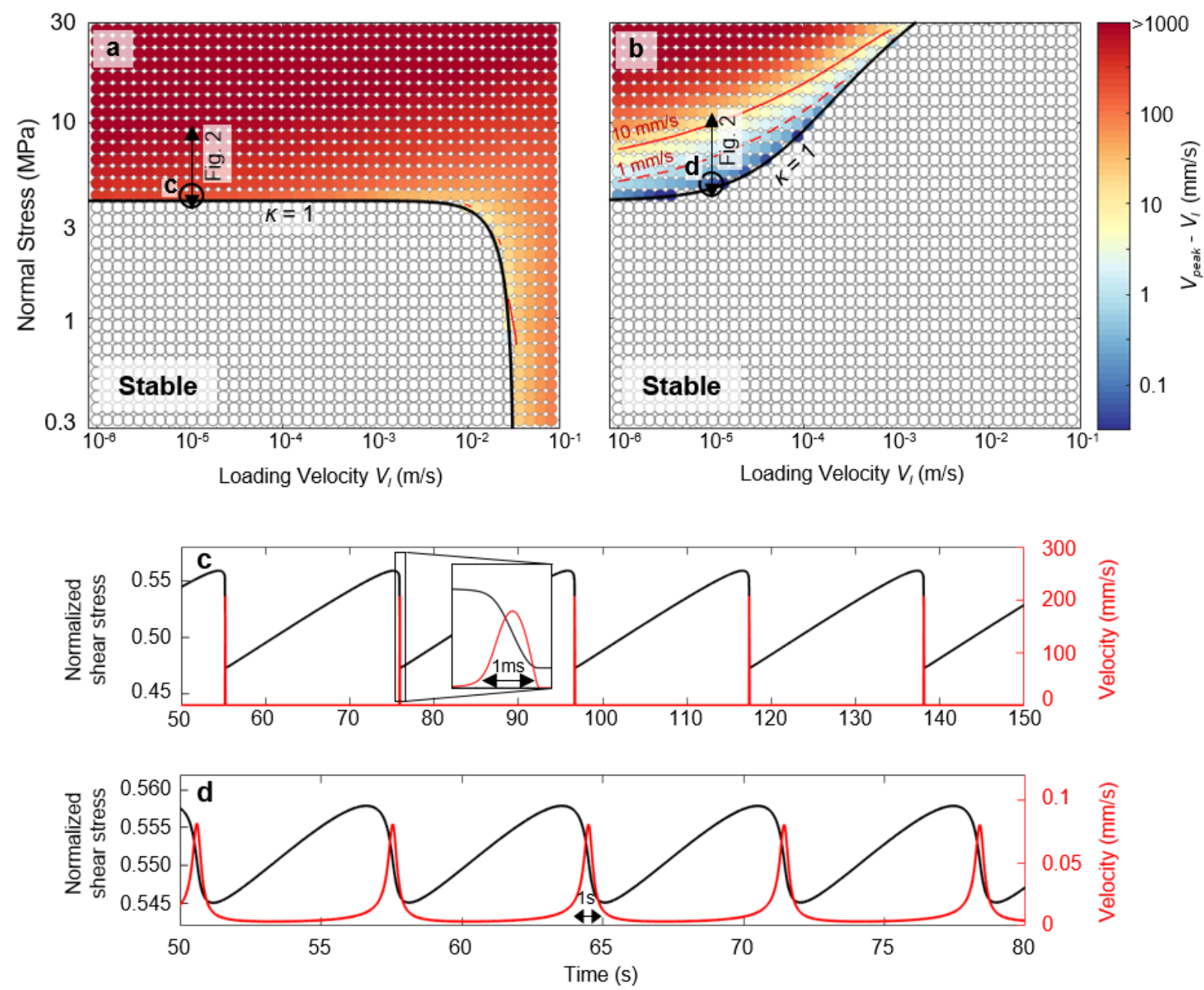

Fig. 1. Conditions for episodic slow slip. Evolution of modeled peak slip velocity for constant RSF parameters (a) and velocity dependent $D_{\mathrm{c}}$ and $a$ (b). See Extended Data Fig. 1 for cases showing the separate effects of velocity dependence of $\mathrm{D}_{\mathrm{c}}$ and $a$. Filled circles represent unstable periodic oscillations (e.g., in Panel c\&d). Empty circles denote stable sliding. Bold black line denotes analytically calculated stability criterion $(\kappa=1)^{25}$. c, d: limit cycle oscillation of normalized shear stress (black), $K\left(\delta_{\mathrm{lp}}-\delta\right) / \sigma$, and velocity (red) for closest case to $\kappa=1$ at $V_{1}=10^{-5}$ $\mathrm{m} / \mathrm{s}$. See methods for details. 

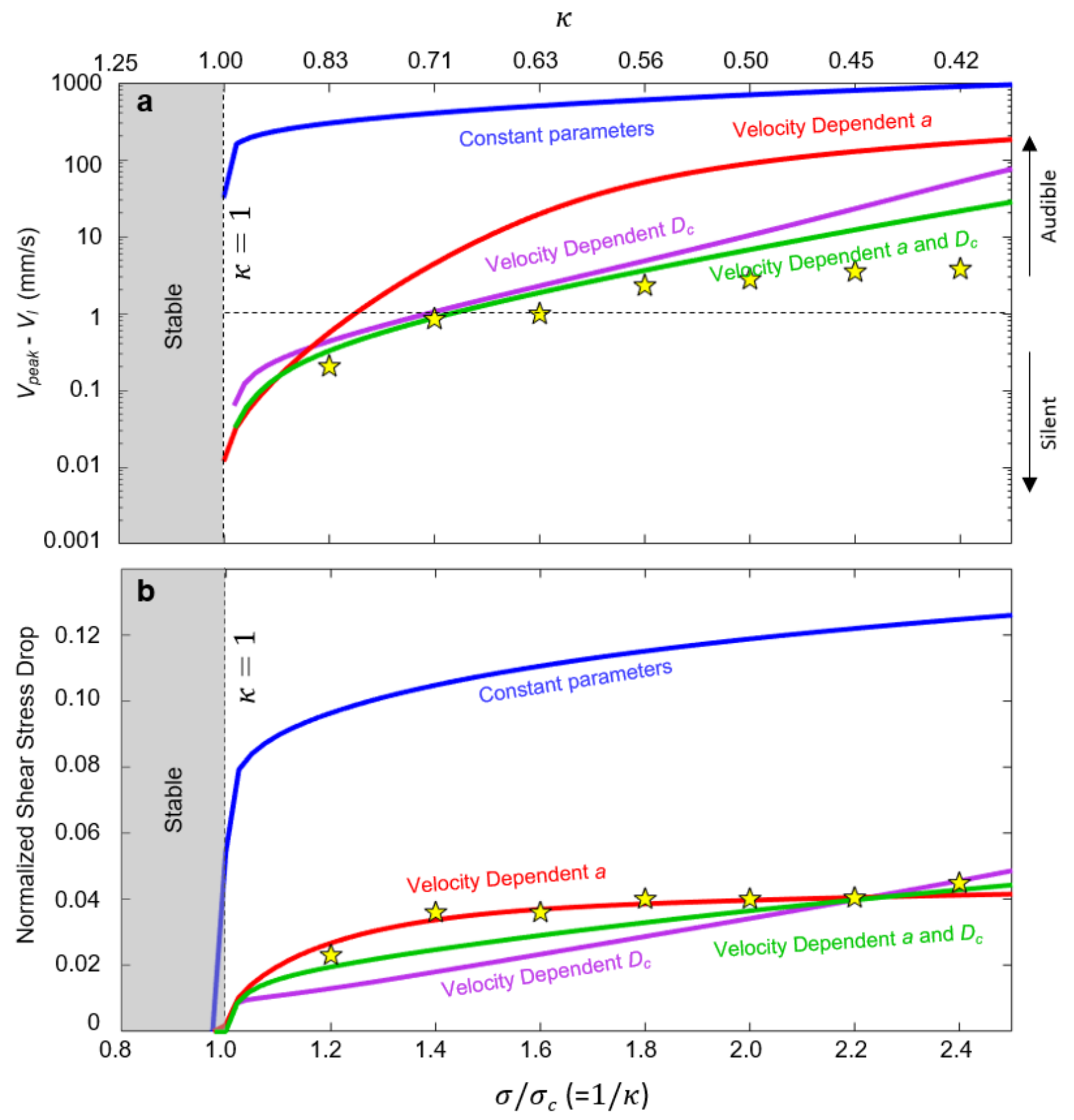

Fig. 2. Peak velocity (a) and normalized stress drop (b) as a function of $\boldsymbol{\kappa}$. The loading velocity is $10 \mu \mathrm{m} / \mathrm{s}$. For constant and velocity dependent $a$ and $D_{c}$ we use the same parameters as in Fig. 1 (see Methods for detailed input parameters). X-axis is normalized by the normal stress at the stability transition $(\kappa=1)$; upper $\mathrm{x}$ axis shows corresponding values of $\kappa$. Yellow stars denote experimental results ${ }^{16}$. Models with rate-dependent RSF parameters predict slow stick slip $(V<1$ $\mathrm{mm} / \mathrm{s}$ ) for values of $\kappa$ as low as $\sim 0.7$. 

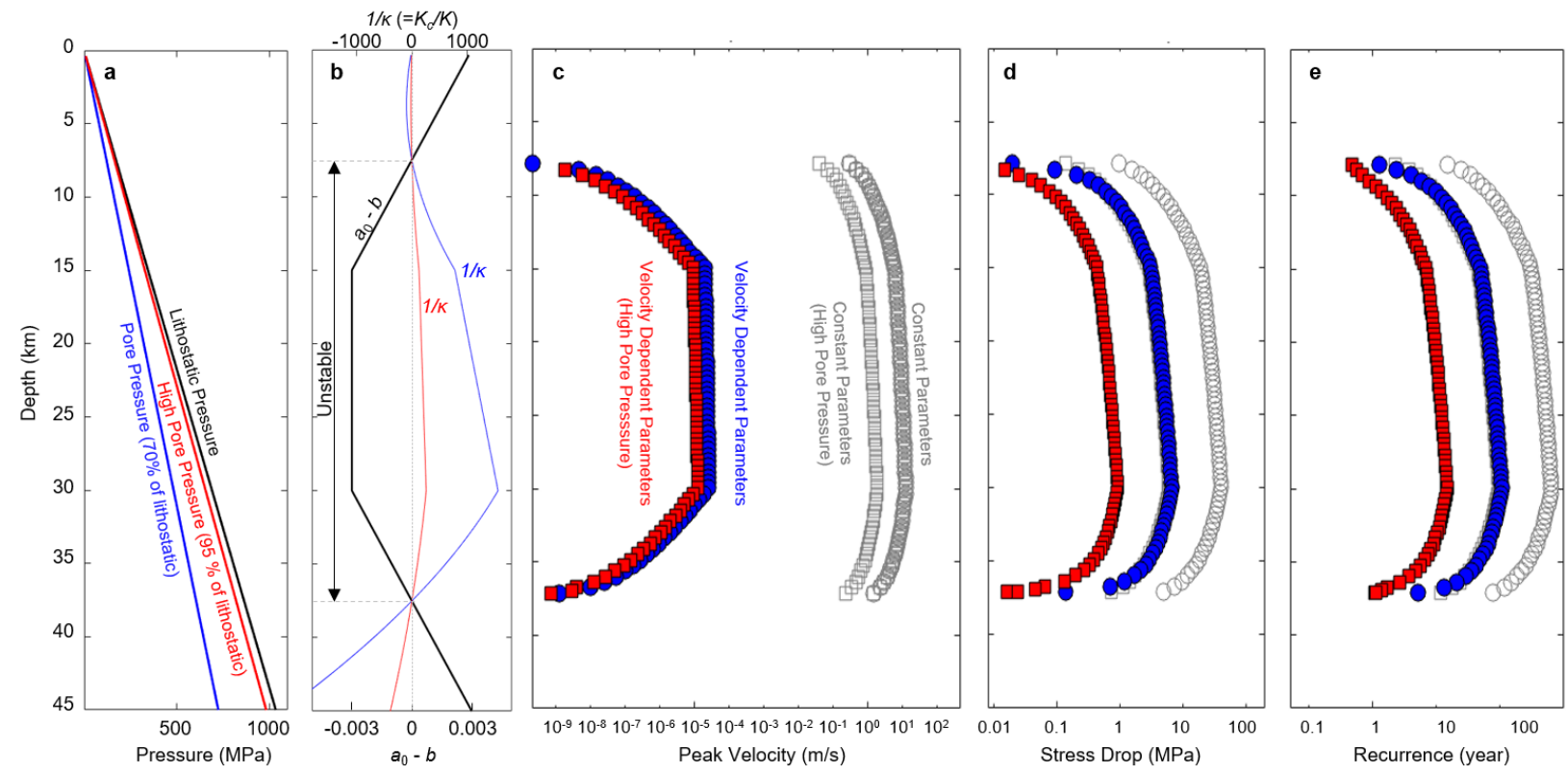

Fig 3. Characteristics of stick-slip events as a function of depth for a generic subduction megathrust. Each circle in $\mathbf{c}, \mathbf{d}$ and $\mathbf{e}$ represents single-degree-of-freedom simulation results using normal stress and $a 0^{-} b$ shown in $\mathbf{a}$ and $\mathbf{b}$. Colored lines denote pore pressures $70 \%$ (blue) and $95 \%$ (red) of lithostatic stress. Red and blue line in $\mathbf{b}$ represent inverse of $\kappa$ (unstable at positive). $\mathbf{c}$ : Simulated peak slip velocity $\mathbf{d}$ : stress drop e: recurrence for velocity dependent parameters (both $a$ and $D_{\mathrm{c}}$; colored) and constant parameters (regular RSF; grey). 

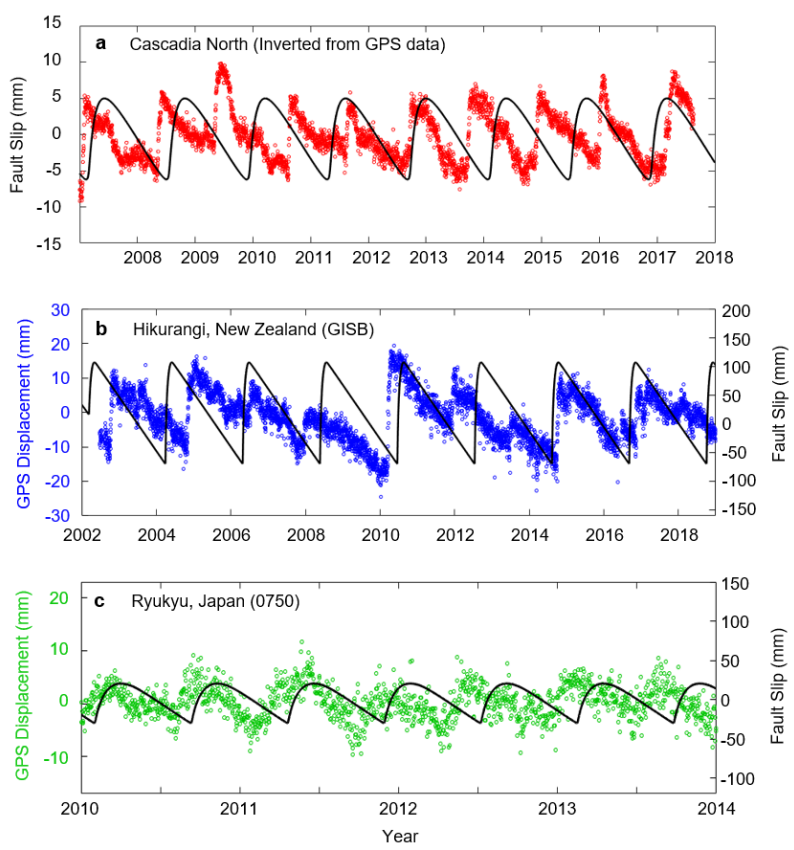
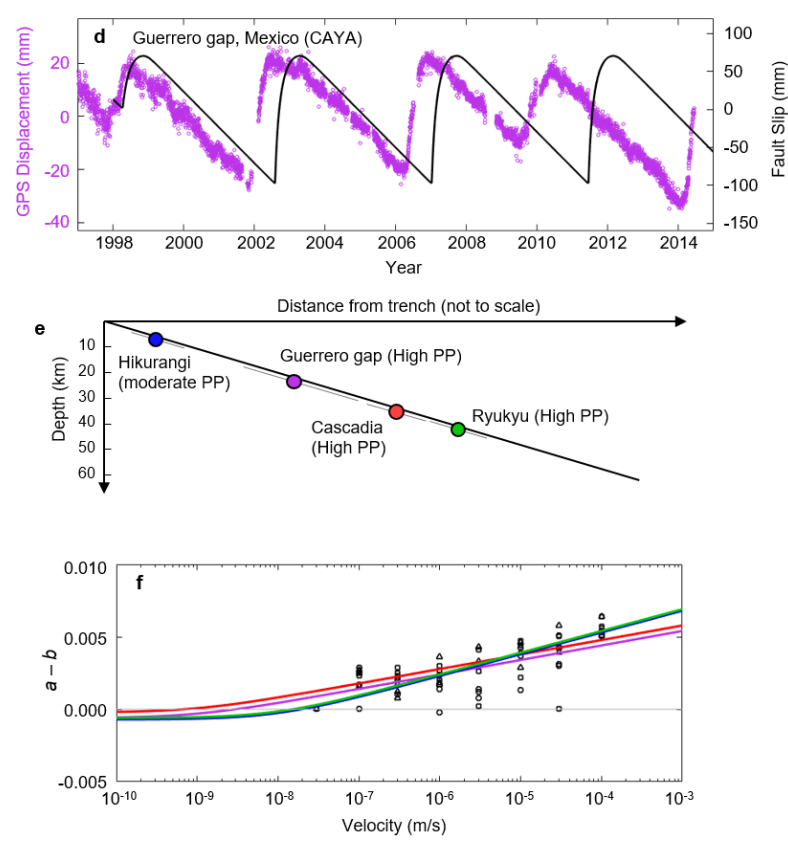

Fig. 4. Comparison with observed Slow Slip Events. Estimated slow slip history (colored dots) and simulations (black lines) for examples of repeating SSEs observed at the Cascadia ${ }^{33}$ (a), Hikurangi $^{6}$ (b), Ryuku ${ }^{34}$ (c) and Mexican megathrusts ${ }^{35}$ (d). (e): schematic section of subduction megathrust showing the estimated depths of SSE for the case examples and equivalent fault length used in the simulations ( $L=50 \mathrm{~km}$ for the Guerrero gap on the Mexican megathrust, $L=20 \mathrm{~km}$ for all others). Pore pressure is set to $97.5 \%, 70 \%, 95 \%$, and $95 \%$ of lithostatic pressure for the Cascadia, Hikurangi, Ryukyu and Guerrero gap simulations respectively. The velocity dependence of $a-b$ for each simulation (f) is color-coded as in the other panels and the symbols show experimental data for $a-b^{27}$ (also see extended Data Fig. 3). 

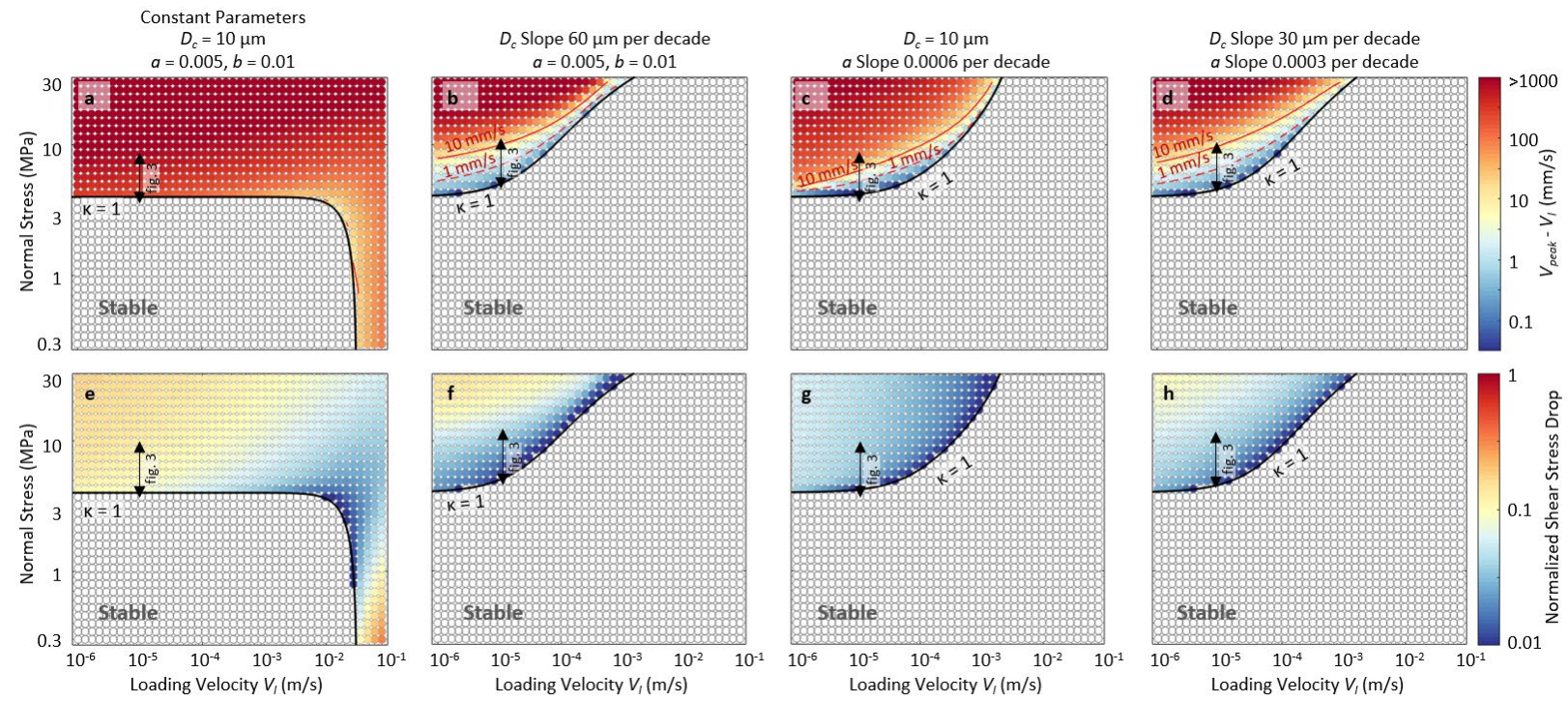

\section{Extended Data Fig. 1}

Evolution of peak velocity and stress drop with stability transition. a,e: constant parameter, $\mathbf{b , f : ~ v e l o c i t y ~ d e p e n d e n t ~} D_{c}, \mathbf{c}, \mathbf{g}$ : velocity dependent $a, \mathbf{d}, \mathbf{h}$ : velocity dependent $D_{\mathrm{c}}$ and $a$ cases. Panels a and d are identical to Figure $1 \mathbf{a}$ and $1 \mathbf{b}$, respectively. We used, $D_{c 0}=10 \mu \mathrm{m}, S_{\mathrm{Dc}}=60$ $\mu \mathrm{m}$ and $V_{D c}=100 \mu \mathrm{m} / \mathrm{s}$ for velocity dependent $D_{c}$ and $a_{0}=0.005, S_{\mathrm{a}}=0.0003, V_{a}=100 \mu \mathrm{m} / \mathrm{s}$ for velocity dependent $a$ simulations. 

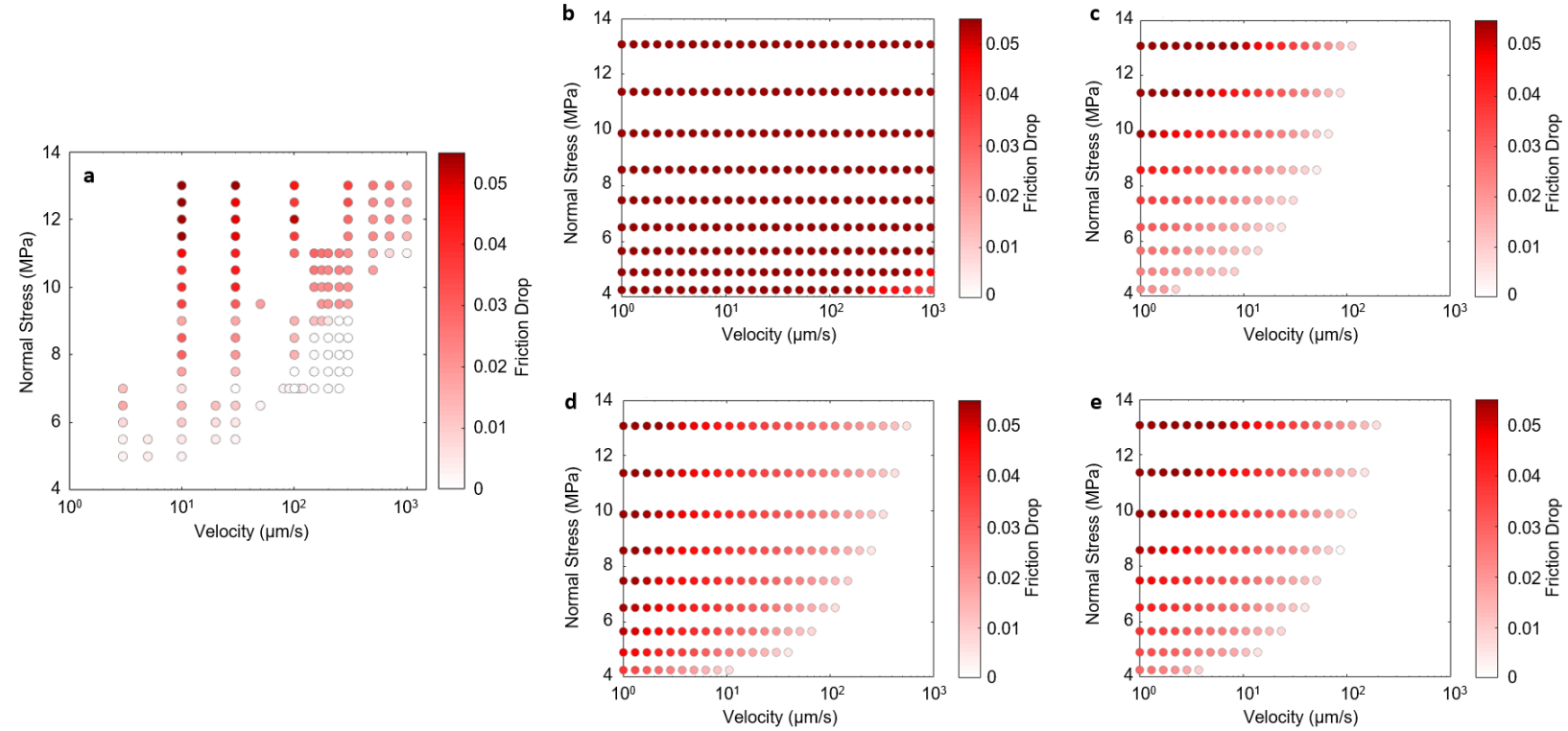

\section{Extended Data Fig. 2}

Comparison of stability transition between laboratory data and simulation results. Friction drop as a function of normal stress and loading velocity for $\mathbf{a}$ : laboratory experiments ${ }^{16}$, and $\mathbf{b}-\mathbf{e}$ : simulations with $\mathbf{b}$ : constant parameters, c: velocity dependent $D_{\mathrm{c}}$, d: velocity dependent $a$, and

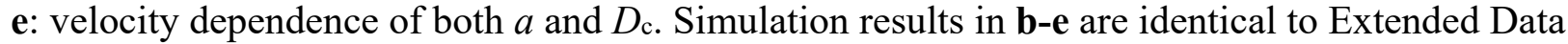
Fig. 1e-h, but re-sized to match the laboratory results of Panel a. 

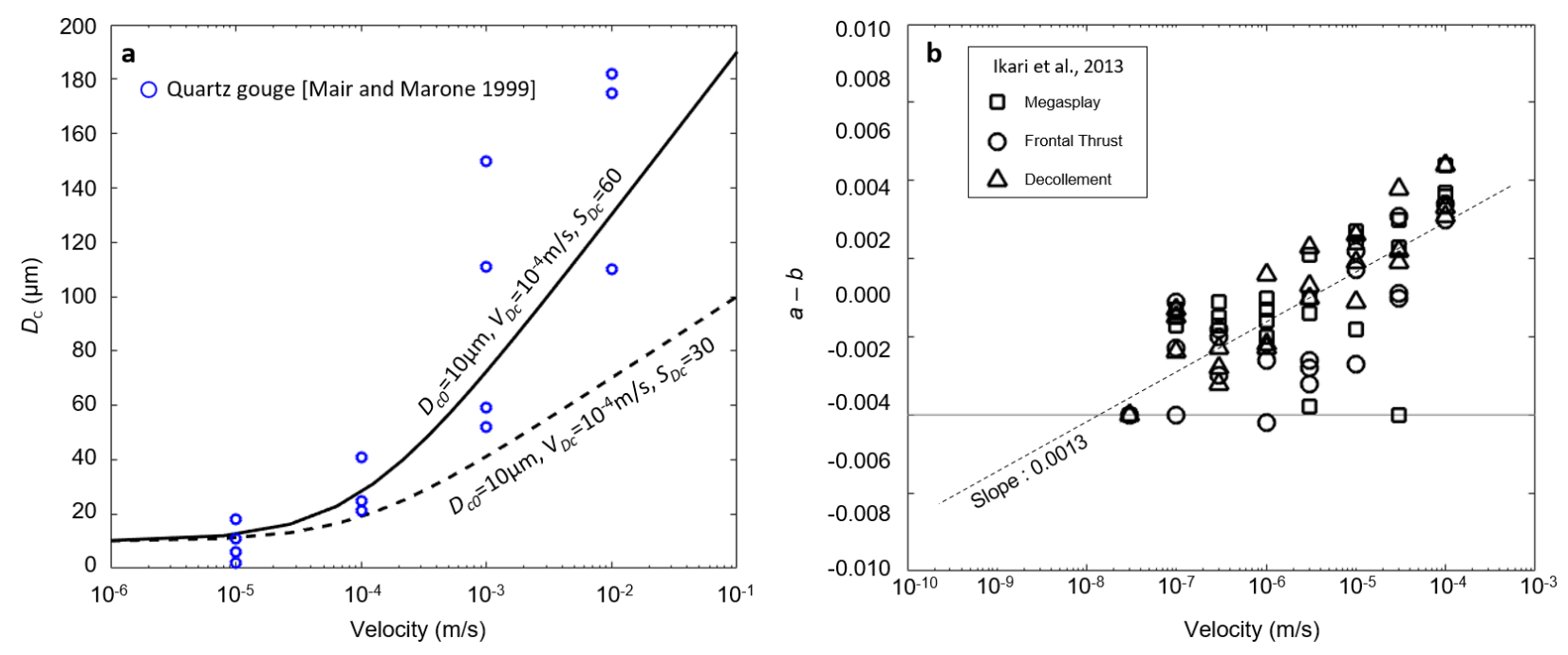

\section{Extended Data Fig. 3}

Experimental data for velocity dependence of friction parameters. a: Experimental data showing $D_{c}$ as a function of sliding velocity for quartz gouge ${ }^{25}$. Blue circles are measurements and solid line represents the velocity dependence we used in our laboratory scale simulations (Figures 1 and 2). For tectonic fault zone simulations, we used identical $S_{\text {Dc, but with }} D_{\mathrm{c} 0}=100$ $\mu \mathrm{m}$ and $V_{D c}=10^{-9} \mathrm{~m} / \mathrm{s}$. b: Compiled experimental data for $a-b$ on tectonic fault zone materials ${ }^{27}$. Dashed line denotes the trend line of all measurement. We used the slop of the trendline $(0.0013$ per decade) for upscaled (Figure 3) simulations. 

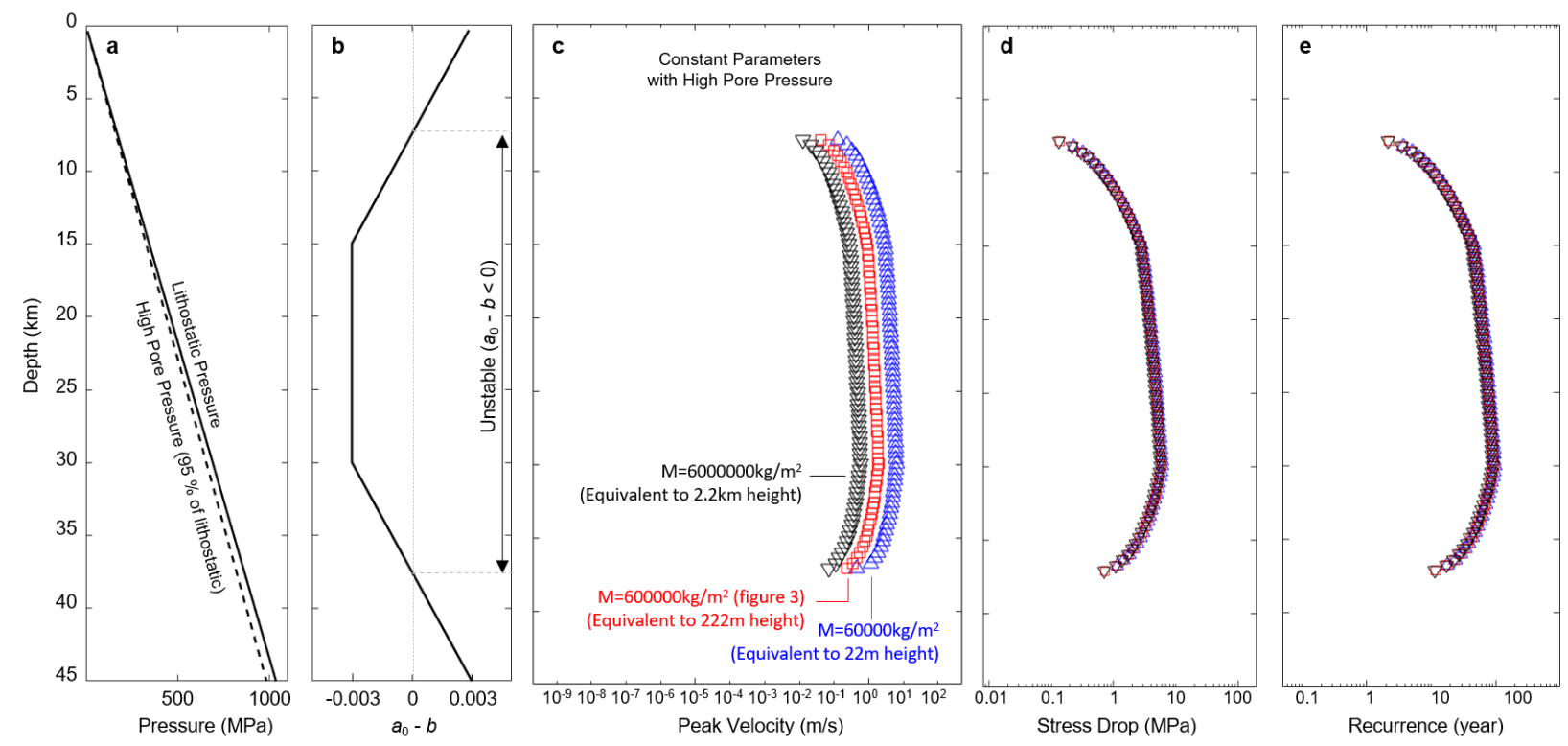

Extended Data Fig. 4

Influence of simulation mass on earthquake slip rate. Here we only considered constant parameter RSF cases, with high pore pressure. Red squares $\left(M=600000 \mathrm{~kg} / \mathrm{m}^{2}\right)$ are case identical to that shown in fig. 3. Blue and black squares show cases with one order of magnitude smaller and larger mass, respectively. Panel c shows that the peak velocity is dependent on the mass. However, even we assume significantly larger mass, stick slip abruptly evolves to fast rupture $\left(V_{\text {peak }}>1 \mathrm{~cm} / \mathrm{s}\right)$ at the transition. 

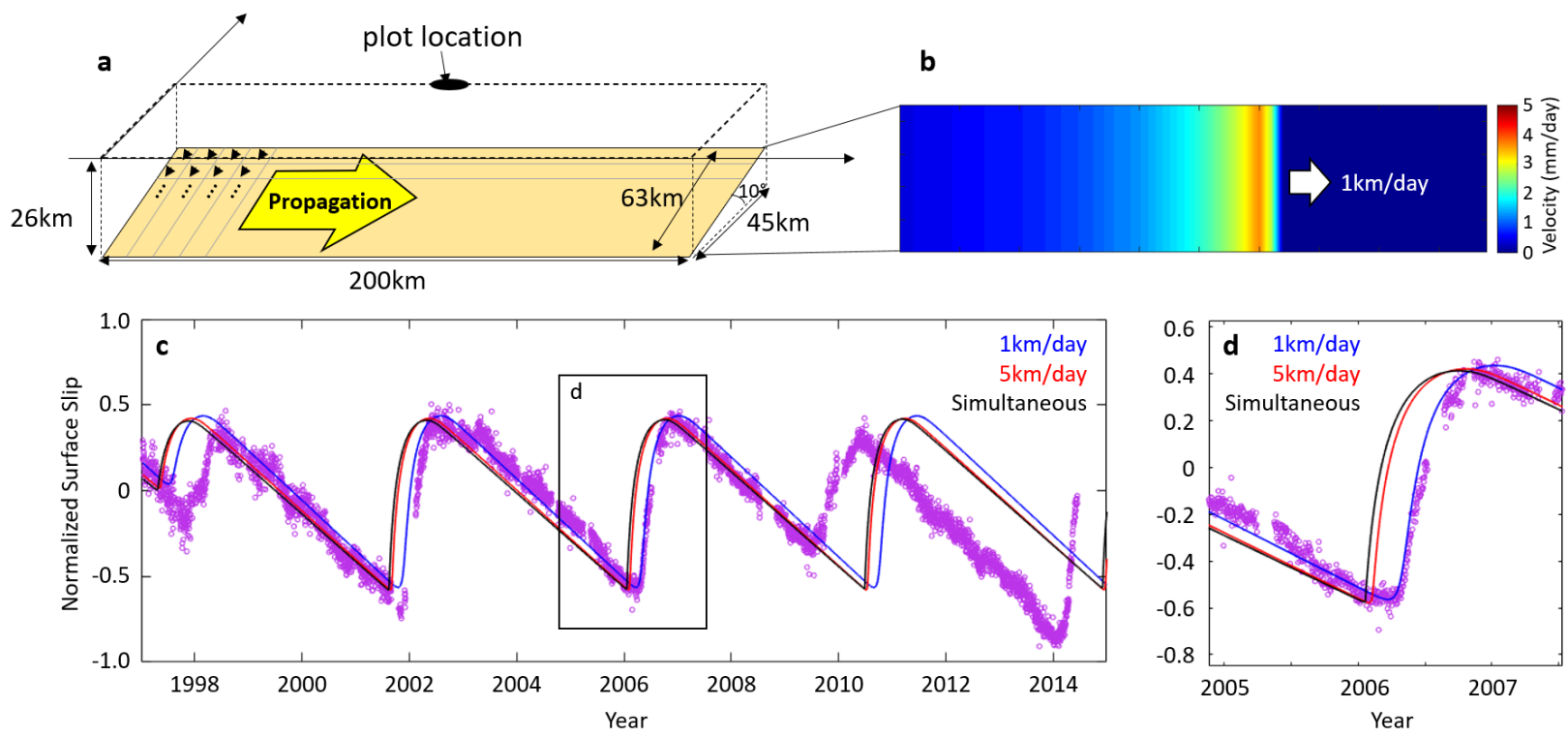

\section{Extended Data Fig. 5}

Simple kinematic model for slip propagation. a: Model illustration. We assume $200 \mathrm{~km} \times 63$ $\mathrm{km}$ slipping patch (light yellow) embedded in a half space with its lower edge at a depth of 26 $\mathrm{km}$. For displacement of each patch, we impose the time evolution of slip derived from the spring-slider model adjusted to the Guerrero example (Fig. 4d). We considered three cases for slip propagation along the strike direction at: (i) $1 \mathrm{~km} /$ day, (ii) $5 \mathrm{~km} /$ day, and (iii) a case with simultaneous slip in the entire patch. Panel $\mathbf{b}$ shows an example of slip propagation for the $1 \mathrm{~km} /$ day case. The fault slip is converted to surface deformation using an elastic dislocation (Okada) model ${ }^{47}$ and the normalized displacements are plotted in panels $\mathbf{c} \& \mathbf{d}$ for comparison with the observed Guerrero gap GPS timeseries. The result shows that the case with a propagation rate of $5 \mathrm{~km} / \mathrm{day}$ (red) is nearly indistinguishable from the case of simultaneous slip (equivalent to an infinitely fast propagation). The case with $1 \mathrm{~km} /$ day (blue) which is at the lower end of the typical rate of propagation of SSEs, is also only slightly altered by the effect of the propagation. 